\title{
Colistin-associated acute kidney injury in intensive care unit patients: Significance of other confounding factors
}

\author{
Samaneh Shariatmaghani ${ }^{1}$, Somayeh Sadat Shariatmaghani ${ }^{2}$, Alireza Sedaghat ${ }^{3}$, Mona Najaf \\ Najafi $^{4}$ and Ahmad Bagheri Moghaddam ${ }^{3 *}$
}
${ }^{1}$ Department of Anesthesia, Vascular and Endovascular Research Center, Mashhad University of Medical Sciences, Mashhad, Iran.
${ }^{2}$ Department of Internal Medicine, Faculty of Medicine, Mashhad University of Medical Science, Mashhad, Iran.
${ }^{3}$ Department of Anesthesia, Faculty of Medicine, Lung Disease Research Center, Mashhad University of Medical Science, Mashhad, Iran.
${ }^{4}$ Clinical Research Unit, Mashhad University of Medical Science, Mashhad, Iran.

Accepted 6 August, 2019

\begin{abstract}
Colistin is a valuable antibiotic for controlling gram-negative pathogens, but the associated nephrotoxicity is an important side effect which limits its use. This study aimed to evaluate the incidence of colistin-associated nephrotoxicity and the role of other confounding factors in the incidence of acute kidney injury (AKI) in critically ill patients. In this prospective cohort study, all patients over 18 years with a positive culture for Acinetobacter baumannii who admitted to ICUs from March 2017 to February 2019 were enrolled. They were divided into two groups; the study group received colistin but the control group consisted of patients who were positive for Acinetobacter culture but due to unavailability of the drug, colistin was not prescribed. Demographic data and clinical characteristics were recorded in a designed questionnaire. The primary outcome was the occurrence of renal failure based on the KDIGO criteria. In total 115 patients were studied, $75(65.2 \%)$ cases and $40(39.8 \%)$ controls. The incidence rate of AKI in the colistin and control groups was 48 and $17.5 \%$, respectively indicating a statistically significant difference $(P=0.033)$. AKI was established on average in the first 6 days of colistin administration. There is no significant difference between the daily and total dose of colistin consumption in patients with AKI and without AKI in the colistin group. After adjusting the confounding variables such as the age of patients, use of simultaneous and potentially nephrotoxic drugs and hypotensive episodes we get an Odds Ratio of 2.48 with a $95 \%$ Confidence interval of 0.97 to 6.36 and a P-value of 0.059 . Colistin is an antibiotic with potential capability for AKI development in ICU patients; however, its incidence in critically ill patients is associated with factors other than colistin as well.
\end{abstract}

Keywords: Colistin, acute kidney injury, nephrotoxicity, Acinetobacter baumannii.

*Corresponding author. E-mail: BagheriA@mums.ac.ir. Tel: 00989155027269.

\section{INTRODUCTION}

The intensive care unit (ICU) is a ward in which invasive procedures such as intratracheal intubation and catheterization are more commonly performed compared to other hospital wards. Longer ICU stay or undergoing mechanical ventilation and other invasive procedures increase the risk of infection. The rate of nosocomial infections and antibiotic resistance varies in different nations, different hospitals and different wards in one hospital. Antibiotic resistance has led to the use of broadspectrum antibiotics, which itself increases the rate of multidrug-resistant (MDR) gram-negative infections (Biberoğlu, 1997; İnan et al., 2002; Camkıran et al., 2011; Grochowalska et al., 2017).

Polymyxin $\mathrm{E}$ or colistin is a valuable antibiotic for controlling gram-negative pathogens, but the associated nephrotoxicity is an important side effect which limits its 
use (Nation et al., 2019). Despite being discovered a long time ago, due to the concern regarding its nephrotoxicity and the availability of other less nephrotoxic drugs, its application was ignored for many years. However, today because of the global distribution of MDR gram-negative pathogens, it is being used as the last line treatment for most Enterobacteriaceae such as Acinetobacter baumannii and Pseudomonas aeruginosa ( $\mathrm{Li}$ et al., 2006).

Colistin is a cationic lipopeptide antibiotic which is prescribed intravenously as colistimethate sodium (CMS), an inactive prodrug; it turns into an active substance in the body. CMS is excreted via secretion through renal tubules (Orwa et al., 2001; Li et al., 2004). There is a clear overlap between the plasma concentration of polymyxin in the therapeutic and toxic levels that can complicate the appropriate drug dosage selection, and its precise selection, especially in high-risk patients (old age, obese, with multiple underlying diseases and the need for simultaneous consumption of other nephrotoxic drugs), is of great importance (Nation et al., 2019). A rise in colistin plasma concentration to $2.5 \mathrm{mg} / \mathrm{L}$ increases the risk of nephrotoxicity (Sorlí et al., 2013; Forrest et al., 2017).

The findings of some studies show that despite not reaching optimal plasma concentration, clinical improvement is still observed indicating that the plasma concentration of colistin is not related to clinical improvement (Sorlí et al., 2017; Dalfino et al., 2012; Sorli et al., 2019). Therefore, an increase in the drug dosage to reach the recommended dose can result in nephrotoxicity progression (Sorlí et al., 2013; Forrest et al., 2017). On the other hand, rapid treatment termination by physicians due to their fear of renal injury can lead to increased drug resistance, whereas the drug-associated nephrotoxicity is usually reversible (Sorli et al., 2019; Javan et al., 2015).

Renal failure is not a contraindication for colistin administration and only dose adjustment is required in such cases. (Sorli et al., 2019; Honore et al., 2013).

In general, the risk factors for colistin-associated nephrotoxicity include dosage and duration of treatment, simultaneous prescription of other nephrotoxic drugs, old age, sex, hypoalbuminemia, hyperbilirubinemia, accompanying underlying diseases and the severity of the present illness (Javan et al., 2015).

In this study, we aimed at evaluating the incidence of colistin-associated nephrotoxicity in the ICU of one of the largest referral hospitals in Iran. Moreover, the role of other confounding factors in the incidence of acute kidney injury (AKI) in critically ill patients was also studied.

\section{MATERIALS AND METHODS}

This prospective cohort study was conducted on adult patients admitted to general and burn ICUs of Imam Reza hospital, Mashhad, Iran from March 2017 to February 2019. All patients over 18 years with a positive culture for Acinetobacter baumannii were enrolled. In this study, we did not select patients with normal kidney function. They were divided into two groups; the study group received colistin but due to low drug availability at some times and despite a positive culture, we had to use antibiotics other than colistin for the control group. The choice of patients in the control group was compulsory; because at some periods, there was no colistin in Iran at all.

All cases with end-stage renal disease (ESRD) undergoing dialysis, pregnant patients, those with a history of recent cardiopulmonary resuscitation, mean arterial pressure (MAP) $\leq 60$ $\mathrm{mmHg}$ before drug administration and those with septic shock were excluded from the study.

Demographic data including age, sex, weight and clinical characteristics such as the site of infection, underlying disease and its severity based on Acute Physiology, Age, Chronic Health Evaluation II (APACHE II) criteria were recorded in a designed questionnaire.

Before starting treatment, creatinine clearance was calculated and recorded daily up to two weeks. Also, urine output was measured every $2 \mathrm{~h}$. during colistin therapy. The patients were also evaluated for simultaneous consumption of other nephrotoxic drugs such as aminoglycosides, vancomycin, amphotericin B, NSAIDs, intravenous contrast media and diuretics. $\mathrm{N}$-acetyl cysteine was also considered in all patients due to its probable preventive effects for renal failure.

The colistin dosage was selected based on colistin base activity (CBA) and consultation with an infectious diseases specialist as 2.5 - $5 \mathrm{mg} / \mathrm{kg}$ daily in two separate doses. In case of a rise in creatinine level above the normal range, it was readjusted according to the creatinine clearance rate.

After collecting the required data, the primary outcome measure which was the occurrence of renal failure based on the Kidney Disease: Improving Global Outcomes (KDIGO) criteria (Figure 1) (a rise in creatinine $\geq 0.3$ in $48 \mathrm{~h}$ or $\geq 1.5$ times during one week or a decrease in urine output to $\leq 0.5 \mathrm{cc} / \mathrm{kg} / \mathrm{h}$. for $6 \mathrm{~h}$ ) was evaluated (Khwaja, 2012).

In this questionnaire, the severity of the renal injury was determined in three stages based on changes in creatinine level and urine output volume (Khwaja, 2012). Moreover, the patients' clinical data including body temperature, arterial $\mathrm{pH}$, sodium, potassium, heart rate, blood pressure, respiratory rate and white blood cell count at admission was recorded and used along with demographic data, Glasgow Coma Score (GCS) and previous medical history for calculating the APACHE II score.

No intervention was performed in this study and the study protocol was approved by the Ethics Committee of Mashhad University of Medical Sciences.

\section{Statistical analyses}

The collected data were entered into the SPSS software, ver. 23. All observations were initially described using descriptive statistics including frequency tables, frequency distribution charts and statistical indices of central tendency and dispersion. KolmogorovSmirnov test was used to determine the data distribution normality. To compare the quantitative variables between the two groups in case of normal data distribution, independent t-test was used. Mann-Whitney test was applied for non-normally distributed data and qualitative (ordinal) variables. Chi-square test and Fisher's exact test were used for comparing qualitative data between the two groups. The significance level was set at $\mathrm{P}<0.05$ for all tests.

\section{RESULTS}

In total 115 patients were studied, $75(65.2 \%)$ cases and $40(39.8 \%)$ controls. The patients' mean age was 


\begin{tabular}{lll} 
Stage & Serum creatinine & Urine output \\
\hline 1 & $1.5-1.9$ times baseline & $<0.5 \mathrm{ml} / \mathrm{kg} / \mathrm{h}$ for $6-12 \mathrm{~h}$ \\
& OR & \\
& $\geq 0.3 \mathrm{mg} / \mathrm{dl}(\geq 26.5 \mu \mathrm{mol} / \mathrm{l})$ & \\
& increase & \\
& $2.0-2.9$ times baseline & $<0.5 \mathrm{ml} / \mathrm{kg} / \mathrm{h}$ for $\geq 12 \mathrm{~h}$ \\
3 & 3.0 times baseline & $<0.3 \mathrm{ml} / \mathrm{kg} / \mathrm{h}$ for $\geq 24 \mathrm{~h}$ \\
& OR & OR \\
& Increase in serum creatinine & Anuria for $\geq 12 \mathrm{~h}$ \\
& to $\geq 4.0 \mathrm{mg} / \mathrm{dl}(353.6 \mu \mathrm{mol} / \mathrm{l})$ & \\
& OR & \\
& Initiation of renal replacement \\
& therapy & \\
& OR, in patients $<18$ years, decrease \\
& in eGFR to $<35 \mathrm{ml} / \mathrm{min}$ per $1.73 \mathrm{~m}^{2}$
\end{tabular}

Figure 1. The severity of renal injury based on the KDIGO criteria.

$46.19 \pm 23.1$ and $58.02 \pm 19.09$ yrs, respectively, indicating a meaningful difference $(P=0.006)$. The demographic data and medical characteristics of the two studied groups are presented in Table 1.

The rate of oliguria was compared in the AKI and noAKI groups, indicating no significant difference $(P=0.25)$.

Comparison of primary disease etiologies and infection sites between the study and control groups are presented in Figures 2 and 3.

In the study group, the meantime of colistin administration was $14.31 \pm 8.04$ days (range: 2 to 43 days). The median colistin daily dosage was three MIU (range: 1 to $6 \mathrm{MIU}$ ) and the mean total colistin dosage was 27 MIU (range: 12 to $198 \mathrm{MIU}$ ). Table 2 displays the total and daily dosage of colistin in patients who experienced AKI after drug therapy and those in whom the renal function remained normal.

Regarding the AKI stage, 15 (57.7\%), four (15.4\%) and seven $(26.9 \%)$ cases in stages I, II and III received colistin with a daily dosage of less than four MIU, respectively. The same figures were nine $(75 \%)$, three (25\%) and zero (0\%) for the $\geq 4$ MIU group; based on Mann-Whitney test no difference was observed between the two groups in this respect $(P=0.243)$.

\section{DISCUSSION}

Nosocomial infections are one of the main causes of mortality and morbidity among inpatients and particularly ICU hospitalized patients. Today, the rise in MDR gramnegative pathogens has encouraged physicians to further use colistin in their treatment strategy. Acinetobacter baumanni has been reported as the most common nosocomial infection among elderly ICU hospitalized patients (Aitullina et al., 2019; Inci et al., 2018; Inci et al.,
2016).

This organism was also the most common infectious pathogens among our studied cases. Based on the literature, pneumonia is the most prevalent infection site among ICU patients (Inci et al., 2018; Dewan and Shoukat, 2014; Hür et al., 2014). In the current study, the most commonly involved sites were the lungs and skin due to pneumonia and burns. The reason for skin infection predominance was the selection of patients from the burn ICU. Nevertheless, the two studied groups were similar in terms of sex, ICU hospitalization period, baseline creatinine level and the APACHE score.

In general, the results of studies on colistin-associated nephrotoxicity in hospitals and different clinical settings are very different (Pogue et al., 2015). This difference can be attributed to individual differences, prescribed daily doses, and the use of different criteria for AKI evaluation in different societies such as risk, injury, failure, loss, end-stage (RIFLE), Acute Kidney Injury Network (AKIN) (Bagshaw et al., 2008) and KDIGO (Khwaja, 2012). In the present study, the incidence rate of AKI based on the KDIGO criteria in the colistin and control groups was 48 and $17.5 \%$, respectively indicating a statistically significant difference $(P=0.033)$. AKI was established on average in the first 6 days of colistin administration. Evaluation of kidney function in critically ill patients is a controversial issue. Estimated Glomerular Filtration Rate (GFR) based on serum creatinine level has many limitations such as the dependency of serum creatinine level on age and sex, nutrition and body mass index. However, it is still used as a guide for determining the adjusted dosage of drugs. There is insufficient information on biomarkers which can be used in the diagnosis of colistin-associated nephrotoxicity (De Lange, 2013). Kim and Kim reported the possible role of plasma Neutrophil gelatinase-associated lipocalin (NGAL) in the 
Table 1. Demographic and clinical characteristics of the study and control group.

\begin{tabular}{|c|c|c|c|c|}
\hline & & Study group & Control group & $\mathbf{P}$ \\
\hline \multicolumn{2}{|l|}{ Age (yr) (Mean \pm SD) } & $46.19 \pm 23.10$ & $58.02 \pm 19.09$ & 0.006 \\
\hline \multicolumn{2}{|l|}{ Gender (M-F) N (\%) } & $48-27(64-36)$ & $20-20(50-50)$ & 0.146 \\
\hline \multicolumn{2}{|l|}{ Duration of ICU stay (days) (Min-Max) } & $29(1-223)$ & $28(10-214)$ & 0.918 \\
\hline \multicolumn{2}{|l|}{ APACHE score (Mean \pm SD) } & $13.99 \pm 4.53$ & $15.65 \pm 4.38$ & 0.06 \\
\hline \multicolumn{2}{|l|}{ Cr level at baseline mg/dl (median) (Min-Max) } & $0.9(0.5-5.2)$ & $0.9(0.4-4.1)$ & 0.74 \\
\hline \multicolumn{2}{|l|}{ Diuretic use N (\%) } & $20(26.7)$ & $13(32.5)$ & 0.510 \\
\hline \multicolumn{2}{|l|}{$\mathrm{N}$-acetylcysteine (NAC) use $\mathrm{N}(\%)$} & $28(37.3)$ & $18(45)$ & 0.424 \\
\hline \multicolumn{2}{|l|}{ Meropenem use N (\%) } & $39(52)$ & $31(77.5)$ & 0.008 \\
\hline \multicolumn{2}{|l|}{ Vancomycin use N (\%) } & $46(61.3)$ & $28(70)$ & 0.355 \\
\hline \multicolumn{2}{|l|}{ Daily Urine Volume (ml) (Mean $\pm S D)$} & $2111 \pm 1626$ & $2414 \pm 1623$ & 0.37 \\
\hline \multirow{4}{*}{ Prevalence of oliguria $(<500 \mathrm{ml} / 24 \mathrm{hr}) \mathrm{N}(\%)$} & None & $63(84)$ & $33(82.5)$ & \multirow{4}{*}{0.827} \\
\hline & First day & $1(1.3)$ & $2(5)$ & \\
\hline & Second day & $5(6.7)$ & $1(2.5)$ & \\
\hline & After the third day & $6(8)$ & $4(10)$ & \\
\hline \multicolumn{2}{|l|}{ A positive fluid balance of $>1000 \mathrm{ml}$ in $24 \mathrm{hr} \mathrm{N}(\%)$} & $63(90)$ & $28(71.8)$ & 0.014 \\
\hline \multicolumn{2}{|l|}{ Mean arterial pressure $\leq 65 \mathrm{mmHg} \mathrm{N}(\%)$} & $27(38)$ & $4(10)$ & 0.003 \\
\hline \multicolumn{2}{|l|}{ Acute Kidney Injury prevalence N (\%) } & $36(48)$ & $11(17.5)$ & 0.033 \\
\hline \multirow{3}{*}{$\begin{array}{l}\text { Acute Kidney Injury stage } \\
\mathrm{N}(\%)\end{array}$} & Stage I & $23(63.9)$ & $7(63.6)$ & \multirow{3}{*}{0.87} \\
\hline & Stage II & $6(16.7)$ & $3(27.3)$ & \\
\hline & Stage III & $7(19.4)$ & $1(9.1)$ & \\
\hline
\end{tabular}

\section{Chart Title}

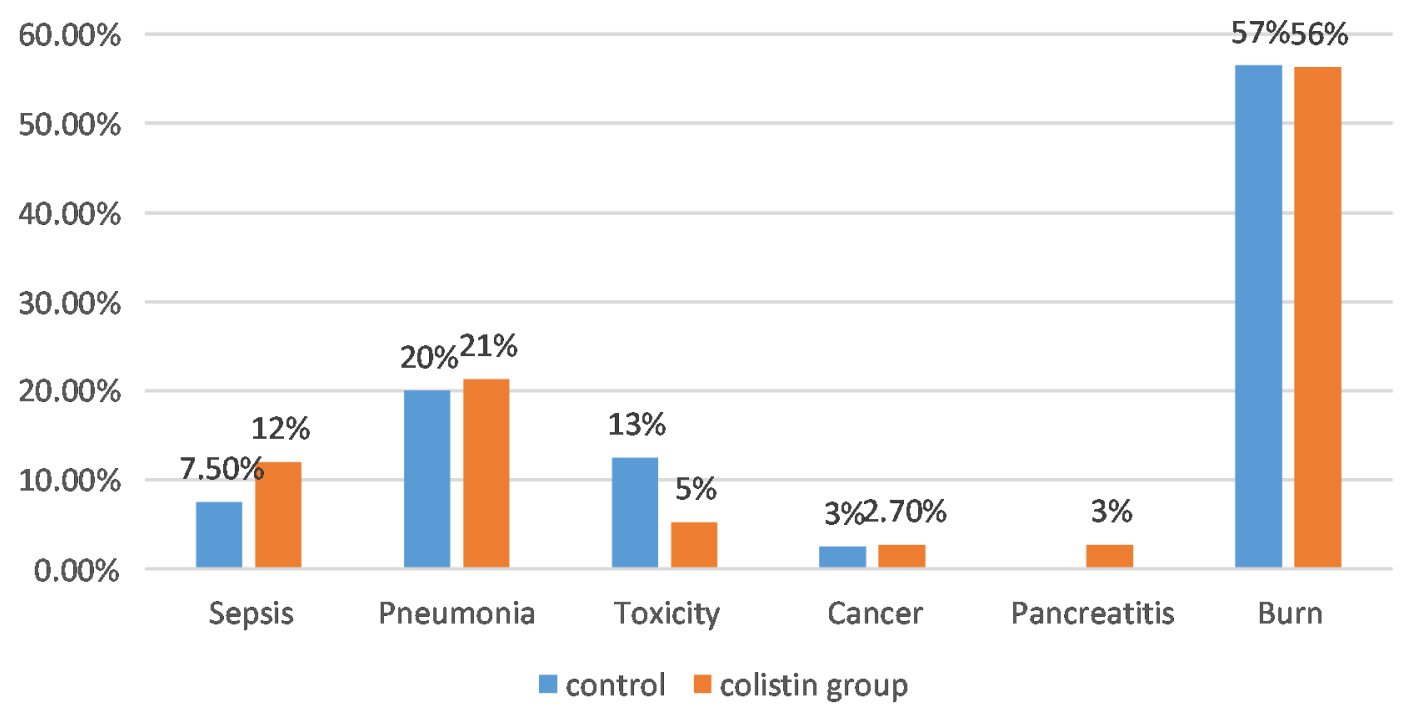

Figure 2. Comparison of primary disease etiologies between the study and control groups.

earlier diagnosis of this condition (Kim and Kim, 2018). Therefore, studying the new generation of biomarkers for the early diagnosis of colistin-associated AKI is highly recommended aimed at increasing treatment efficacy without nephrotoxicity development (Kim and Kim, 2018).
In the study by Ko et al. (2011), AKI was reported in $54.6 \%$ of those receiving colistin among which $70 \%$ experienced renal injury in the first 7 days. They stated that the earlier incidence of $\mathrm{AKI}$ is associated with higher mortality. In Dalfino et al. (2015) study the drug- 


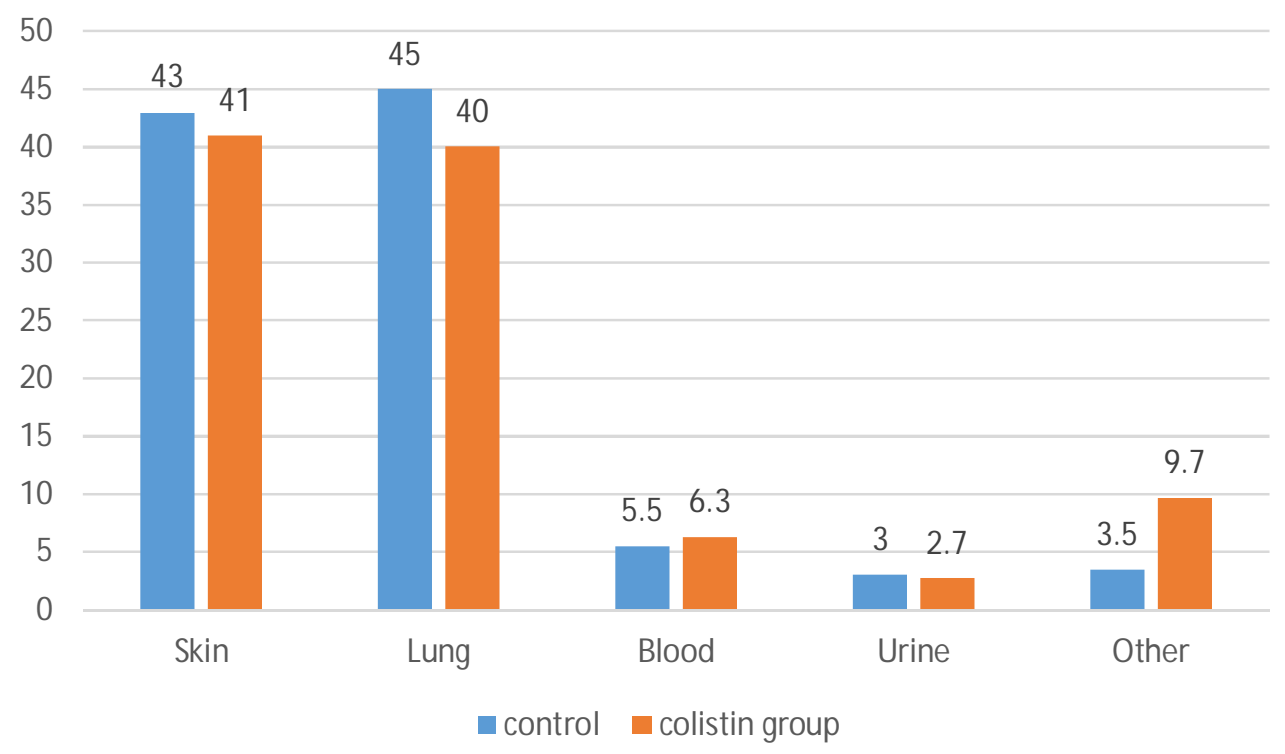

Figure 3. Comparison of infection sites between the study and control groups.

Table 2. Comparison of daily and total colistin dosage in patients with and without acute kidney injury (AKI).

\begin{tabular}{lccc}
\hline Colistin group & AKI & No AKI & P \\
\hline$<4$ MIU/day N (\%) & $24(48)$ & $26(52)$ & $>0.99$ \\
$\geq 4$ MIU/day N (\%) & $12(48)$ & $13(52)$ & 0.93 \\
Colistin total dose (MIU) (mean \pm SD) & $44.07 \pm 34.75$ & $43.36 \pm 42.97$ & 0 \\
\hline
\end{tabular}

associated $\mathrm{AKI}$ was reported as $42 \%$ in stage I, most commonly occurring in the first 5 days of treatment. On the other hand, in a prospective study with 3-9 MIU/day CMS administration, AKI was observed in the first 7 days in $25.5 \%$ of the cases whereas in $49 \%$ it was seen at the end of the treatment course (Sorlí et al., 2013). The rate of colistin-associated nephrotoxicity in Aitullina et al. (2019) study was $22 \%$ with a mean onset of 7.5 days, mostly in stage I and II. This figure was reported as 54\% in another study on ICU patients under colistin therapy (Inci et al., 2018). In general, the rate of AKI in critically ill patients has been reported as 10 to $49 \%$ (Javan et al., 2015).

In the present study, $63.9 \%$ of the AKI cases in the study group experienced a stage I AKI, similar to that of the control group (63.6\%). Our studied patients received different doses of CMS as 1 to 6 Million International Units (MIU)/day based on patient's body weight and their creatinine clearance level. This dose variation suggests that there are no clear and specified recommendations (guidelines) on dosage adjustment. The instructions of the manufacturing companies are only applicable for noncritical patients and physicians generally use different handbooks and articles for this purpose (Aitullina et al., 2018). According to Honore et al. (2013) study, patients under renal replacement therapy (RRT) in an ICU received higher doses such as $4.8 \mathrm{MIU} / \mathrm{q} 8 \mathrm{~h}$; it was justified by the hypothesis that colistin is absorbed and wasted through the hemodialysis filter; whereas in another study for ICU patients under similar conditions, a reduced dosage of colistin was administered. In Aitullina et al. (2019) study, patients under colistin therapy who had heterogeneous renal function received different doses of this drug. Therefore, the appropriate dose needs to be clearly defined to prevent the increased risk of renal injury without reducing the drug's antimicrobial effectiveness (Nation et al., 2019). In the present study, the cases in the colistin group in whom AKI occurred were compared with no-AKI cases regarding the daily and total dose of colistin consumption, revealing no significant difference. However, an increased risk of AKI has been reported with an increase in colistin dosage in other studies (Biswas et al., 2012; Lee et al., 2015). This difference in results can be due to not using very high doses of colistin in our study; performing further studies applying the standard doses mentioned in related guidelines is highly recommended.

Unfortunately, most of the colistin-associated AKI related factors are not justifiable. Moreover, certain chronic and multiple comorbid conditions in severely ill 
patients such as old age (Katip et al., 2017; Temocin et al., 2015) and diabetes increase drug-associated renal injury (Sorlí et al., 2013).

However, there are also several risk factors, which can be corrected such as the lesser use of simultaneous nephrotoxic drugs, loop diuretics (Gul et al., 2016), vancomycin and aminoglycosides (Temocin et al., 2015).

In the current study, the patients in the colistin group were much younger than the control group [06]; regarding the higher rate of $\mathrm{AKI}$ in this group despite the lower age range, it can be concluded that another important factor, and not age, has played a role in this respect.

The most commonly used antibiotic in the control group was meropenem, which is significantly different from that of the study group $(77.5 \%$ versus $52 \%)$ (Table 1$)$. If meropenem could be involved in causing renal injury in the control group, given that AKI incidence was significantly more in the study group, it can be concluded that the role of colistin in AKI occurrence is more prominent. AKI stage in the colistin and the control group was not significantly different and colistin-associated AKI was mild and mostly in stage I (Table 1).

In the present study, the study and control groups were similar in terms of the administration of other nephrotoxic drugs, such as loop diuretics and vancomycin.

Some evidence has shown a decreased risk for colistin-associated AKI in the combination therapy of colistin with other diuretics (Dai et al., 2017; Lodise et al., 2018). In a randomized controlled trial, the isolated effect of colistin was compared with the combination of colistin and meropenem against gram-negative pathogens. The incidence of AKI was $48 \%$ in the monotherapy and $29 \%$ in the combined therapy group ( $P=0.001)$. Based on the RIFLE criteria the rate of injury was $14 \%$ vs. $6 \%$ and the failure rate was $17 \%$ vs. $8 \%$ in the two groups (Paul et al., 2018). In a meta-analysis colistin-related nephrotoxicity was also higher in the monotherapy group (OR: 1.66; $\mathrm{Cl}<95 \%$ : 0.99-2.78; $\mathrm{P}=0.05$ ) (Wang et al.,
2019). It is hypothesized that in combination therapy the effect of oxidative stress is reduced causing a milder inflammatory response or better recovery from sepsis leading to reduced organs (such as kidneys) dysfunction; this highlights the need for further studies in the future (Nation et al., 2019).

The precise monitoring of renal function during the treatment course along with sufficient fluid therapy and electrolyte balance maintenance are essential factors in reducing the risk of colistin-associated AKI (Zavascki and Nation, 2017).

The two studied groups were also compared regarding the amount of fluid intake in which the colistin group had received a significantly greater amount of serum regarding the positive balance of $>1000 \mathrm{cc}$ fluids in comparison to controls; the reason was the higher use of colistin in burn ICU patients compared to general ICU cases. In spite of the higher fluid intake, the rate of AKI was significantly higher in the colistin group compared to the controls; however, the mean urine volume and oliguria frequency were similar between the two groups.

Following drug administration the prevalence of a mean arterial blood pressure $<65 \mathrm{mmHg}$ was significantly higher in the colistin group which could be attributed to the higher severity of the disease in this group and the higher need for colistin administration in these patients. The drop in MAP may also have played a role in the occurrence of renal injury in such patients.

In general, the rate of renal injury in the colistin group was significantly higher than the control group $(P=0.035)$. After adjusting the confounding variables including age, meropenem usage, positive balance of $>1000 \mathrm{cc}$ fluids and $\mathrm{MAP}<65 \mathrm{mmHg}$, the chance ratio was achieved as $\mathrm{OR}=2.48 ; \quad \mathrm{Cl}=0.97-6.36, \quad \mathrm{P}=0.059 \quad$ (Table 3). The incidence of $\mathrm{AKI}$ in the colistin group is associated with factors other than colistin; therefore in case of choosing colistin for patients, care should be taken to minimize other factors affecting the incidence of AKI.

Table 3. Interaction of variables.

\begin{tabular}{lccc}
\hline Variable & OR & Cl & P-value \\
\hline Age $\geq 60$ yrs & 1.66 & $0.72-3.48$ & 0.236 \\
Meropenem usage & 2.257 & $0.902-5.649$ & 0.082 \\
$\geq 1000 c c$ fluids balance & 1.007 & $0.326-3.112$ & 0.991 \\
MAP $\leq 65$ mmHg & 1.67 & $0.648-4.320$ & 0.287 \\
Colistin consumption & 2.48 & $0.97-6.36$ & 0.059 \\
\hline
\end{tabular}

\section{Conclusion}

Colistin is an antibiotic with potential capability for AKI development in ICU patients; however, its incidence in critically ill patients is associated with factors other than colistin as well. The appropriate dosage of colistin and controlling other modifiable risk factors such as hemodynamic optimization and limiting the use of other nephrotoxic drugs may reduce colistin-associated AKI.

\section{ACKNOWLEDGMENTS}

This article is based on Research Plan No. 950676 
Approved Date: 10/2/2018 and Ethics Committee Authorization No. IR.MUMS.fm.REC.1395.623.

This project is funded by the Vice-Chancellor for Research and Technology of Mashhad University of Medical Sciences.

\section{REFERENCES}

Aitullina A, Krūmiña A, Cauce V, Purvina S, 2018. Colistin Use Patterns and Toxicity in Critically III Patients in Pauls Stradinš Clinical University Hospital. Proceedings of the Latvian Academy of Sciences Section B Natural, Exact, and Applied Sciences: Sciendo.

Aitullina A, Krūmina A, Svirskis S, Purvina S, 2019. Colistin use in patients with extreme renal function: From dialysis to augmented clearance. Medicina, 55(2): 33.

Bagshaw SM, George C, Bellomo R, 2008. A comparison of the RIFLE and AKIN criteria for acute kidney injury in critically ill patients. Nephrol Dialysis Transplant, 23(5): 1569-1574.

Biberoğlu K, 1997. Intensive care unit infections - Risk factors. Epidemiol Prevent Flora, 2: 79-84.

Biswas S, Brunel JM, Dubus JC, Reynaud-Gaubert M, Rolain JM, 2012. Colistin: an update on the antibiotic of the 21st century. Expert Rev Anti-infect Ther, 10(8): 917-934.

Camkıran A, Kundakcı A, Araz C, Pirat A, Zeyneloğlu P, Arslan H, 2011. Cerrahi yoğun bakım ünitesinde çok ilaca dirençli Acinetobacter baumannii enfeksiyonunun ön belirleyicileri: retrospektif bir analiz. J Turk Soc Intens Care, 9:53-58.

Dai C, Ciccotosto GD, Cappai R, Wang Y, Tang S, Xiao X, Velkov T, 2017. Minocycline attenuates colistin-induced neurotoxicity via suppression of apoptosis, mitochondrial dysfunction and oxidative stress. J Antimicrob Chemother, 72(6): 1635-1645.

Dalfino L, Puntillo F, Mosca A, Monno R, Spada ML, Coppolecchia S, Miragliotta G, Bruno F, Brienza N, 2012. High-dose, extendedinterval colistin administration in critically ill patients: is this the right dosing strategy? A preliminary study. Clin Infect Dis, 54(12): 17201726.

Dalfino L, Puntillo F, Ondok MJM, Mosca A, Monno R, Coppolecchia S, Spada ML, Bruno F, Brienza N, 2015. Colistin-associated acute kidney injury in severely ill patients: a step toward a better renal care? A prospective cohort study. Clin Infect Dis, 61(12): 1771-1777.

De Lange D, 2013. Glomerular hyperfiltration of antibiotics. Neth J Crit Care, 17: 10-14.

Dewan A, Shoukat M, 2014. Evaluation of risk of nephrotoxicity with high dose, extended-interval colistin administration. Indian J Crit Care Med, 18(7): 427.

Forrest A, Garonzik SM, Thamlikitkul V, Giamarellos-Bourboulis EJ, Paterson DL, Li J, Silveira FP, Nation RL, 2017. Pharmacokinetic/toxicodynamic analysis of colistin-associated acute kidney injury in critically ill patients. Antimicrob Agents Chemother, 61(11): e01367-17.

Grochowalska A, Kozioł-Montewka M, Sobieszczańska A, 2017. Analysis of Acinetobacter baumannii resistance patterns in patients with chronic obstructive pulmonary disease (COPD) in terms of choice of effective empiric antibiotic therapy. Ann Agric Environ Med, 24(2): 307-311.

Gul S, Kuscu F, Aydemir H, Ozturk DB, Deveci O, Duygu F, Kacmaz B, Yaman F, Aslan E, 2016. Risk factors for colistin-associated acute kidney injury: a multicenter study from Turkey. Japan J Infect Dis, 69(2): 109-112.

Honore PM, Jacobs R, Joannes-Boyau O, Boer W, De Waele E, Van Gorp V, Spapen HD, 2013. Continuous renal replacement therapy allows higher colistin dosing without increasing toxicity. J Translat Internal Med, 1(1): 6-8.

Hür E, Çetintürk A, Eminoğlu V, Sungur M, Tavşan Ö, Pişkinpaşa S, 2014. Colistin and acute renal failure: A centre's experience. Turk Neph Dial Transpl, 23: 196-201.

İnan D, Saba R, Keskin S, Öğünç D, Çiftçi C, Günseren F, 2002. Nosocomial infections in Akdeniz University intensive care units. Yoğun Bakım Dergisi, 2(2): 129-35.
Inci A, Karabay A, Erus S, Demiraran Y, 2016. Nosocomial infections and associated risk factors in geriatric patients in the intensive care unit. J Acad Emergency Med, 15(4): 177.

Inci A, Toker MK, Bicer IG, Derbent A, Salihoglu Z, 2018. Determination of colistin-related nephrotoxicity and risk factors in intensive care unit. Northern Clin Istanbul, 5(2): 120.

Javan AO, Shokouhi S, Sahraei Z, 2015. A review on colistin nephrotoxicity. Eur J Clin Pharmacol, 71(7): 801-810.

Katip W, Uitrakul S, Oberdorfer P, 2017. Clinical outcomes and nephrotoxicity of colistin loading dose for treatment of extensively drug-resistant Acinetobacter baumannii in cancer patients. Infect Drug Resist, 10: 293.

Khwaja A, 2012. KDIGO clinical practice guidelines for acute kidney injury. Nephron Clin Pract, 120(4): c179-c84.

Kim EJ, Kim ES, 2018. Exploring new predictors of colistin-associated nephrotoxicity. Infect Chemother, 50(3): 283.

Ko HJ, Jeon MH, Choo JE, Lee JE, Kim HT, Jun JB, Gil HW, 2011. Early acute kidney injury is a risk factor that predicts mortality in patients treated with colistin. Nephron Clin Pract, 117(3): c284-c8.

Lee YJ, Wi YM, Kwon YJ, Kim SR, Chang SH, Cho S, 2015. Association between colistin dose and development of nephrotoxicity. Crit Care Med, 43(6): 118711-93.

Li J, Milne RW, Nation RL, Turnidge JD, Smeaton TC, Coulthard K, 2004. Pharmacokinetics of colistin methanesulphonate and colistin in rats following an intravenous dose of colistin methanesulphonate. $J$ Antimicrob Chemother, 53(5): 837-840.

Li J, Nation RL, Turnidge JD, Milne RW, Coulthard K, Rayner CR, Paterson DL, 2006. Colistin: the re-emerging antibiotic for multidrugresistant gram-negative bacterial infections. Lancet Infect Dis, 6(9): 589-601.

Lodise TP, Fan W, Griffith DC, Dudley MN, Sulham KA, 2018. A retrospective cohort analysis shows that coadministration of minocycline with colistin in critically ill patients is associated with reduced frequency of acute renal failure. Antimicrob Agents Chemother, 62(1): e01165-17.

Nation RL, Rigatto MHP, Falci DR, Zavascki AP, 2019. Polymyxin acute kidney injury: Dosing and other strategies to reduce toxicity. Antibiotics, 8(1): 24

Orwa JA, GOVAERIS C, Busson R, Roets E, Van Schepdael A, Hoogmartens J, 2001. Isolation and structural characterization of colistin components. J Antibiot, 54(7): 595-599.

Paul M, Daikos GL, Durante-Mangoni E, Yahav D, Carmeli Y, Benattar YD, Skiada A, Andini R, Eliakim-Raz N, Nutman A, Zusman O, Antoniadou A, Pafundi PC, Adler A, Dickstein Y, Pavleas I, Zampino R, Daitch V, Bitterman R, Zayyad H, Koppel F, Levi I, Babich T, Friberg LE, Mouton JW, Theuretzbacher U, Leibovici L, 2018. Colistin alone versus colistin plus meropenem for treatment of severe infections caused by carbapenem-resistant Gram-negative bacteria: an open-label, randomised controlled trial. Lancet Infect Dis, 18(4): 391-400.

Pogue JM, Ortwine JK, Kaye KS, 2015. Editorial Commentary: Optimal Usage of Colistin: Are We Any Closer? Oxford University Press.

Sorlí L, Luque S, Grau S, Berenguer N, Segura C, Montero MM, Alvarez-Lerma F, Knobel H, Benito N, Horcajada JP, 2013. Trough colistin plasma level is an independent risk factor for nephrotoxicity: a prospective observational cohort study. BMC Infect Dis, 13(1): 380.

Sorli L, Luque S, Li J, Rodríguez E, Campillo N, Fernandez X, Soldado J, Domingo I, Montero M, Grau S, Horcajada JP, 2019. Colistin use in patients with chronic kidney disease: Are we underdosing patients? Molecules, 24(3): 530.

Sorlí L, Luque S, Segura C, Campillo N, Montero M, Esteve E, Herrera S, Benito N, Alvarez-Lerma F, Grau S, Horcajada JP, 2017. Impact of colistin plasma levels on the clinical outcome of patients with infections caused by extremely drug-resistant Pseudomonas aeruginosa. BMC Infect Dis, 17(1): 11

Temocin F, Erdinc S, Tulek N, Demirelli M, Bulut C, Ertem G, 2015. Incidence and risk factors for colistin-associated nephrotoxicity. Japan J Infect Dis, 68(4): 318-320.

Wang J, Niu H, Wang R, Cai Y, 2019. Safety and efficacy of colistin alone or in combination in adults with Acinetobacter baumannil infection: A systematic review and meta-analysis. Int $\mathrm{J}$ Antimicrob Agents, 53(4): 383-400. 
Zavascki AP, Nation RL, 2017. Nephrotoxicity of polymyxins: is there any difference between colistimethate and polymyxin B? Antimicrob Agents Chemother, 61(3): e02319-16.
Citation: Shariatmaghani S, Shariatmaghani SS, Sedaghat A, Najafi $M N$, M oghaddam AB, 2019. Colistin-associated acute kidney injury in intensive care unit patients: Significance of other confounding factors. Int Res J Med M ed Sci, 7(3): 91-98. 